\title{
Litigation and complaints in the dental practice
}

\section{By Dr Kerry Beynon'}
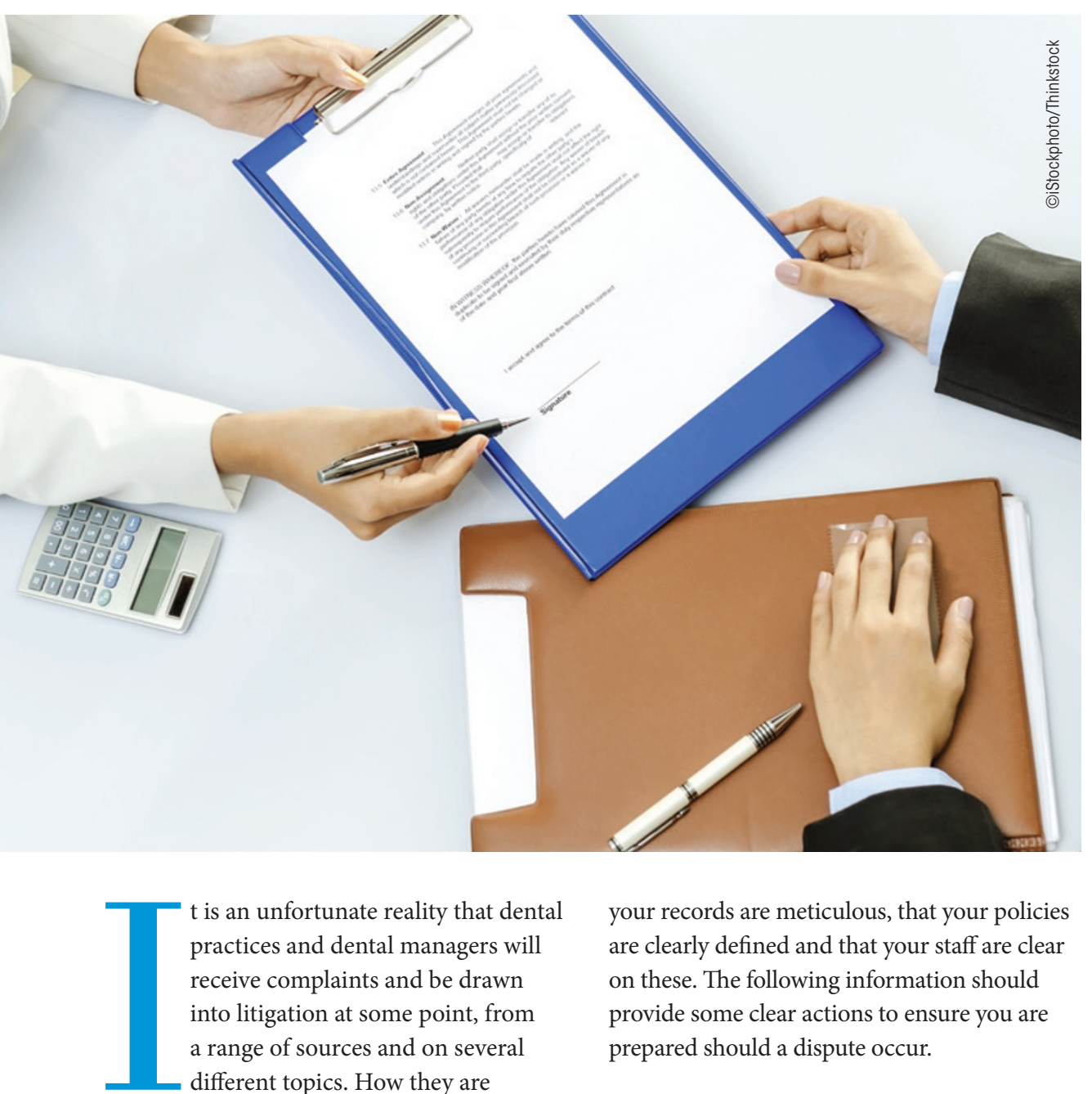

$\mathrm{t}$ is an unfortunate reality that dental practices and dental managers will receive complaints and be drawn into litigation at some point, from a range of sources and on several different topics. How they are handled from the start can determine very different outcomes.

This article will look at some of the most common complaints in dental practices and how they can be avoided, where possible.

The most common types of disputes relevant to dental practice are client care issues, contractual or partnership disputes (including the NHS), and those relating to your trading name or premises. The most crucial way of avoiding any (and all) of these is to ensure

${ }^{1}$ Associate Solicitor and Head of Intellectual Property, JCP Solicitors www.jcp-healthcare.co.uk your client. Try to outline the pros and cons of treatment by using information leaflets at the practice. Manage their expectations from the start and be upfront and clear about what is included within costs and procedures. Should a dispute arise following care, contact your insurance company before taking any other actions and certainly before responding to the complaint. They will advise if you are covered or have acted to manage expectations.

\section{DISPUTE 2 - Contractual disputes with employees and self-employed people}

The most important point with regards to this type of dispute is to ensure your practice manager is up to date with all employment law and all paperwork reflects this (and remember that by law all employees are entitled to a statement of terms of their employment). If a complaint is made, seek HR advice from a dental specialist at the earliest opportunity and ensure all conversations and agreements are documented.

\section{DISPUTE 3 - Partnership disputes}

Disputes between partners in a practice can be incredibly difficult and can especially be a problem where the partnership is one of an expense-sharing nature. Very often partnerships, particularly historic ones, are based on goodwill and 'gentlemen's agreements', but unless contracts have been laid down, the details can become murky. Partnerships must be formalised to ensure all parties are happy
DISPUTE 1- Client care issues
This could involve service falling below the expectations (or perceived expectations) of your records are meticulous, that your policies provide some clear actions to ensure you are prepared should a dispute occur.

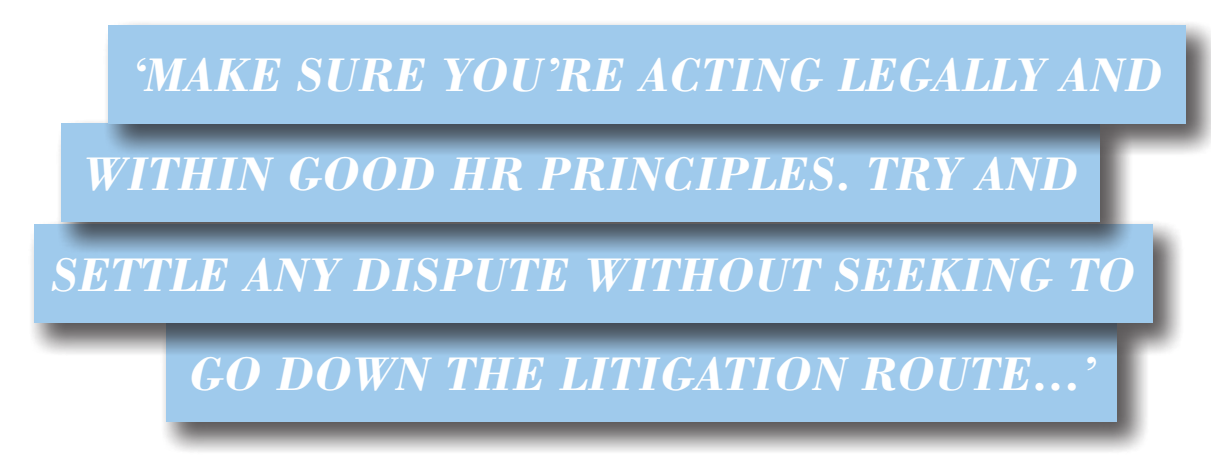


with their legal obligations and any unforeseen circumstances that could arise. Speak to a legal professional who specialises in dental practice to ensure that the partnership agreements are correctly formalised and that both parties are fairly represented.

\section{DISPUTE 4 - Payment disputes \\ with NHS}

NHS payment is made to practices based on agreed target UDAs, and payments for NHS work are usually paid in advance. With this in mind, there are often payments to be returned or contracts to be negotiated if you were to terminate the work. In many instances the decision to relinquish NHS duties is the result of numerous factors including mounting UDA pressures, which in some cases is felt to reduce the standard and quality of care that can be given to each patient.

Keeping thorough records of all work completed and all payments made should assist you with any NHS disputes you may have. The terms of your NHS contract will determine any likely provision for claw back payments already accrued. Details such as these may well have a significant impact on your practice, so make sure that a professional deals with this from the outset.

\section{DISPUTE 5 - Premises}

Disputes with landlords can occur if you are occupying your premises under a lease. With the conversion to a limited company, you must consider including changing the terms of your property lease from a single leaseholder or partnership to a limited company. Ensure your landlord is aware of your business and any changes that are made and that these are amended in your tenancy agreement. Also, do not forget that most leases require your landlord's consent before alterations can be made to a building. Failing to get proper consent to any alterations from your landlord (and planning authorities if necessary) can lead to your lease being terminated.

\section{DISPUTE 6 - Service provider disputes}

Disputes with service providers to your practice can be tricky. Examples could include changing contractors but termination provisions already built into contracts can prevent this. The key here is good practice management. Ensure you keep a central database of contracts and key dates and arm yourself with as much information as possible.

\section{DISPUTE 7- Disputes over}

\section{trading names}

It is surprising how common these types of

\section{The BDJ Team reader panel on COMPLAINTS}

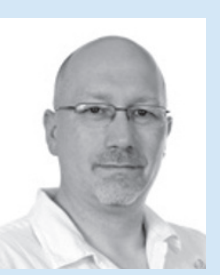

\section{Shaun Howe, dental hygienist}

'The problem for the profession is that patients have the right to complain direct to the GDC (not necessarily the DCS) and this is the primary reason for the increase in complaints... That said, perhaps we, as a profession, should be driving for awareness of PRACTICE complaints procedures rather than patients going direct to the GDC. There are also issues with those that handle cases at the DCS as they are not dentally trained and will refer to FtP if they do not understand the finer points of a complaint.'

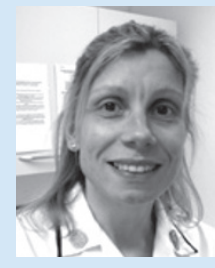

\section{Steph Horner, dental nurse/ decontamination lead}

encouraged to present their complaint through the proper channel according to our practice policy. Complaints are very rare here and they have always been resolved within our practice.

The provision of NHS dentistry has changed since the introduction of UDAs. At the end of the day each practice is a business and needs to run as such. Previously each item of treatment had a fee, so practitioners were paid for any work they carried out. Now you have a lump sum awarded to you and you must spend it accordingly. Go over that budget and you're expected to treat patients for free. Go under the budget and your UDAs are adjusted the following year accordingly. It's quite possible that this has been a major contributing factor to the quality of patient care. Not treatment quality, but customer service. Couple this with the financial crisis over the last few years and you have the making of a very disgruntled public. I expect good service for my money as well as the next person. If I feel I haven't received such I will now complain rather than just pass it off.

This country has also been

encouraged to jump on the American litigation bandwagon, in order to gain some type of financial compensation. It's not difficult to see why, what with the "no win, no fee" ambulance chasers.'

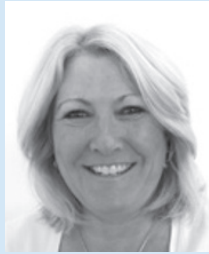

\section{Jacqui Elsden, Dental Education Facilitator}

'Patients are much more aware now than ever before due to the use of the Internet for "looking things up". Patient expectations are higher and our patients often "request treatment" such as cosmetic treatment/implants. If patient expectations are not handled adequately, complaints will follow. disputes are. The key to avoiding them is to look for similar names but also soundalikes as they're just as difficult. Registering your practice name is easy (if it fulfils the legal requirements for a registered trade mark) and registration costs are typically between $£ 250$ - $£ 350$ plus legal fees. When registering, remember that you can only register a name that is distinct - you can't be descriptive, for instance using your location followed by 'dental clinic' forming the name of your practice. Even if you've been operating for years without ever registering your practice name, you still can have a case should someone open something that sounds similar - this is based on the reputation you have built.
It is always good to have a distinct brand identity - from competitors but also if you own multiple practices. Visit the Intellectual Property Office website at www.ipo.gov.uk for further advice and information on this.

My overarching advice to anybody with a private practice is to get your house in order know what's what, who you are dealing with, what your contracts say, when contracts come to an end/can be terminated and where the documents are filed. Make sure you're acting legally and within good employment and HR principles. My advice is to try and settle any dispute without seeking to go down the litigation route - it can be costly.

bdjteam201490 